\title{
Assessing the Economic and Environmental Sustainability of a Regional Air Quality Plan
}

\author{
Claudio Carnevale ${ }^{1}$, Fabrizio Ferrari ${ }^{2}$, Giorgio Guariso ${ }^{3, *(1)}$, Giuseppe Maffeis ${ }^{2}(\mathbb{D}$, \\ Enrico Turrini ${ }^{1}$ and Marialuisa Volta ${ }^{1}$ \\ 1 DIMI, University of Brescia, 25121 Brescia, Italy; claudio.carnevale@unibs.it (C.C.); \\ enrico.turrini@unibs.it (E.T.); marialuisa.volta@unibs.it (M.V.) \\ 2 Terraria Srl, 20125 Milan, Italy; f.ferrari@terraria.it (F.F.); g.maffeis@terraria.it (G.M.) \\ 3 DEIB, Politecnico di Milano, 20133 Milan, Italy \\ * Correspondence: giorgio.guariso@polimi.it; Tel.: +39-02-2399-3559
}

Received: 1 September 2018; Accepted: 2 October 2018; Published: 6 October 2018

\begin{abstract}
Air quality plans must be demonstrated to be economically sustainable and environmentally effective. This paper presents a full cost-benefit and environmental analysis of a large regional air quality plan involving several different actions covering a large spectrum of fields, from domestic heating to passenger and freight transport, from electricity generation to agriculture. The impact of each action is analyzed looking at the possible energy savings, greenhouse gases (GHG) emission reductions, the improvement in air quality, and the consequent decrease in external costs, namely the reduced impact on population health. The analysis is performed by applying a flexible and fast computer tool (RIAT+) that allows for a rapid simulation of different pollutant emission scenario, to assess different air quality indices (AQIs) over a regional scale domain. The results show that, in most cases, the economic savings exceed the implementation costs and thus that these actions can be introduced in air quality plans for the domain under study. The reduced health and climate costs, though relevant in absolute terms, are, in general, only a fraction of the economic benefits of energy savings. This is not true for the measures acting on improvements in electricity generation, since a reduction in power plant emissions (generally with high stacks, far from populated areas) does not significantly impact the air quality inside the region. A shift in energy production to renewable sources can instead provide noticeable effects on GHG emissions. This research raises some interesting and general questions about the adequacy of the methodologies applied to attribute costs (and benefits) to actions, improving a variety of sectors that are different from the one in which the measures are applied here.
\end{abstract}

Keywords: air pollution; secondary pollutants; integrated assessment; health impacts; greenhouse gases

\section{Introduction}

Designing air quality plans is a complex task that goes through a long "line of command" that originates from the indications of the World Health Organization (WHO) and goes down to the local environmental authorities. More precisely, in Europe, WHO's thresholds are used to guide air quality objectives set in EU Directives. The European Commission also defines the type of instruments (measures) that can be adopted to reach such objectives. Recently, most of the practical implementations of these measures fall under the responsibility of local governments (e.g., [1]). This is due to two main reasons. On the one hand, the variation in pollutant emissions affects an area within a hundred kilometer radius from the source, depending also on local meteorological and geomorphological conditions. In this context, air pollution emissions differ from GHG emissions, whose impacts are global. On the other hand, emission abatement measures may be assessed at different scales (from the 
continental to the local one), but they are implemented locally, by authorities aware of the emission sources characteristics. In fact, each domain is characterized by a specific distribution of traffic routes, industrial activities, urban centers, and agricultural areas. This means that specific knowledge of the sources is needed to effectively reduce emissions in different contexts. Many city/local/regional air quality plans have been developed in recent years. These considerations have also been fostered by the EU Directive [2], which requires areas with air quality values below those foreseen by the current norms to design specific improvement plans.

The EU Fp7 APPRAISAL project [3] has recently collected and catalogued several tens of air quality plans from twelve European countries [4]. They have been developed using different approaches focusing on different features, depending on the peculiarities (emissive profile, meteorological, land use, topographical conditions, etc.) of the territory. Almost all plans apply a chemical and transport model (CTM) to assess the effects on air quality of distinct emission abatement actions. Only a small number of plans take into account pollution-related health indicators or the comparison of the internal costs with benefits related to health impacts and energy consumption.

This work considers some of the abatement measures foreseen included in these plans and applies a software tool (RIAT+, [5,6]) to evaluate costs, benefits, and concentration levels determined by the implementation of the air quality plan of Lombardy region, an area in Northern Italy struggling with high levels of air pollution. The paper is organized as follows: the next section exemplifies some local air quality plans to show how various and specific they can be. The Lombardy plan approved in 2013, and currently under revision, is then illustrated. Section 3 presents the adopted method. Section 4 offers an overview of the specific features of the software tool applied for the assessment of the abatement strategies. The following section exposes and comments on the results obtained. The concluding section suggests how such an analysis can be extended to different territorial contexts and which steps have to be further implemented to support the development of efficient plans.

\section{Air Quality Plans: The European State of the Art}

As stated in Air Quality Directive 2008/50/EC Art. 23, air quality plans are the instruments that national and local authorities design and implement to meet ambient air quality standards. Such plans can be built through cost-effective analyses [7] adopting modeling systems.

The methodologies used to identify effective plans can be classified in two main categories [4]; [8]: (1) Scenario analysis [9-11] includes the source-apportionment and the multi-criteria approaches (e.g., ELECTRE [12]; MCDM [13]). Using this approach, a set of abatement measures is first defined by a panel of experts and stakeholders, and its impact is then assessed through the application of a chemical and transport model, with the possibility of modifying the proposed set of measures if they are deemed unsatisfactory under certain viewpoints. (2) The optimization approach includes the multi-objective analysis [14-17], a cost-benefit analysis [18]; [19], and a cost-effective analysis [20-22]. This means that a set of objectives must be defined a priori by a panel of experts and stakeholders, and an automatic algorithm will then determine the set of efficient measures to be implemented.

In Miranda et al.'s work [23], a comparison of air quality plans in Europe is presented. The work highlights how only a limited number of plan presents the cost-benefit analysis (CBA).

The following examples, also collected in the APPRAISAL project database [8], represent applications of the mentioned approaches at different levels of complexity.

The Air Quality Plan (AQP) for Antwerp, in Belgium [24], includes a set of policies with the aim to improve PM10 and NO2 concentrations in the atmosphere and reduce noise levels. A list of measures was compiled by the Antwerp environmental authority based on a combined procedure taking into account expert judgment and source apportionment studies that identified the harbor industry and road transports [25] as major sources of NOx and PM. Different scenarios were simulated by means of the AURORA-OSPM chemical transport modeling system [26,27]at urban and street level to evaluate the impact of selected measures on $\mathrm{NO}_{2}, \mathrm{PM}$, and $\mathrm{EC}$ concentrations and population 
exposure. The health impact evaluation was performed using the DALYs (Disability Adjusted Life Years) indicator, the computed integrating concentration, and population density maps.

Another air quality plan of interest is the one designed for the urban area of Athens, Greece, which is located in a basin open to the sea, surrounded on three sides by mountains. The basin is highly populated and industrialized. Unfavorable meteorological conditions combined with anthropogenic emissions are responsible for the presence of high air pollutant concentrations. A source-apportionment analysis, performed using the Eulerian photochemical model REMSAD, identified industry, central heating, road transport, long-range transport, and re-suspension processes as the main atmospheric pollution drivers for PM10 pollution. A Multi-Criteria Decision Analysis, performed by means of the ELECTRE III method [28], identified a suitable set of abatement strategies, taking into account costs, acceptance, and socio-economic indicators. The pollutant concentrations were simulated using a multi-scale modeling system: the Eulerian model OFIS and the OSPM street scale model.

The AQP for Northern Region of Portugal consists of a measure set defined in collaboration with local stakeholders. It focuses on local measures for traffic (for example, vehicle speed reduction), industrial and residential combustion sectors. The evaluations of the air quality impacts resulting from measure application were performed applying the TAPM model. Effects on population exposure and health were considered indirectly, based on the limit values exceedances according to the European Directive [29].

Altogether, it emerges that, though the link between air pollution and economy has been studied in various contexts (e.g., [30,31]), there are few examples [32,33] of a complete economic and environmental assessment of air quality plans. Additionally, most studies only address the urban dimension where meteorology and emissions are less varying in space and time. This paper deals with a regional and quite inhomogeneous domain and tries to evaluate all the environmental and economic aspects of a plan, knowing that economic sustainability is a key condition for adoption by local authorities. The paper contributions are as follows: to show how different aspects of a regional plan can be evaluated, to point out which sectors are more likely to produce significant economic benefits, and to discuss the problem of including in an air quality plan actions that have a different primary objective.

\section{The Air Quality Plan for the Lombardy Region (PRIA)}

In Lombardy, particularly unfavorable meteorological conditions lead to high air pollution levels that need to be faced by adopting substantial reductions of pollutant emissions.

The regional plan (PRIA), approved in 2013 [34] and updated in 2018, consists in a set of emission abatement measures and predicts the evolution of emissions until 2020. The current revision is aimed at monitoring its state of implementation and devising some additional actions.

The plan consists of 66 measures:

- 26 measures for road and off-road transports;

- 27 measures for point emission and energy efficiency;

- 13 measures for forestry and agriculture.

In its first implementation period, the plan is due to mobilize consistent investments coming from different sectors and not made exclusively to improve air quality. They are planned to reduce the impacts of the following:

- road transport and mobility (excluding highways and high-speed infrastructures)-investments: $€ 2.725 \mathrm{M}$;

- $\quad$ stationary sources and smart use of energy: $€ 63.84 \mathrm{M}$;

- forestry and agricultural activities: $€ 64.79 \mathrm{M}$. 
Emission $E_{p}$ of pollutant $p$ resulting from the application of measure(s) $\underline{u}$ for a cell of a gridded domain, identified by the coordinates $x, y, z$, can be expressed as

$$
E_{p}(x, y, z)=\sum_{i} A_{i}(x, y, z, \underline{u}) \cdot e f_{i p} \cdot\left(1-r_{i p}(\underline{u})\right)
$$

where

- $\quad A_{i}$ is an estimate of the presence of an activity $i$ at point $x, y, z$ of the domain (usually measured in terms of energy consumption);

- $\quad e f_{i p}$ is the "unabated" emission factor of pollutant $p$ by activity $i$, i.e., the emission for a unit activity when none of the abatement measures is applied;

- $\quad r_{i p}(\underline{u})$ represents the fraction of reduced emission of pollutant $p$ by activity $i$ determined by decision $\underline{u}$.

The fraction of reduced emission is the product of two factors: a reduction efficiency, specific of the adopted technology, and an "application rate," the actual decision variable, representing the measure penetration in the $i$-th activity sector.

The horizontal coordinates ( $x$ and $y$ ) identify the horizontal position of a domain cell, while $z$ can only assume two values to separate high or low emissions.

Following Equation (1), the different measures can be classified as follows:

- End-of-pipe measures, which reduce the pollutant emission (almost) without changing the correspondent activity level, i.e., they increase $r_{i p}$ by increasing the penetration of the abatement measure in activity $i$. This means in turn that $r_{i p}$ can, in theory have two limit values: a lower bound value, typically zero, if the technology is not applied), and an upper bound value, the reduction efficiency itself, when the measure is applied to the maximum possible extent $(100 \%)$. End-of-pipe measures consequently do not modify GHG emissions.

- Non-technical measures (including "energy efficiency" strategies), which affect emissions by varying the energy consumption of activity $i$ through changes in production values or processes. This means that a few components of the decision array $u$ modify the value of $A_{i}$. Such changes may correspond to a more efficient (and thus reduced) use of fuels or to a radical modification of the activity, such as substituting car transport with cycling. All these entail a reduction in GHG emissions.

- Scenario measures cannot be applied gradually, so, emission reductions can only be zero or fixed, i.e., the shutdown of an activity, or its relocation. These decisions are also part of $u$ and generally also involve a change in GHG emissions.

Although the classification shown above is adopted in other works (e.g., in GAINS, [20]), it is not univocal. The replacement of old EURO vehicles is commonly considered an end-of-pipe measure even if, in some case, it involves an increase in efficiency.

An important feature of the decision array $u$ is its areal extension. A single set of decisions for each cell $(x, y)$ of the domain is not computationally feasible and may also be difficult to politically justify. It is however possible to define clusters of cells with similar traits or belonging to sub-regional administrative units. For instance, measures involving domestic heating can be applied to urban cells, and agricultural measures can instead be applied to non-urban cells.

\section{The Evaluation Scheme}

\subsection{Methodology}

The overall approach followed for the assessment is sketched in Figure 1 [35]. The definition of a specific scenario (some or all PRIA measures) is split into energy non-technical ones (entailing a certain benefit representing the energy savings) and end-of-pipe ones. Scenario measures are simply dealt 
with by running the overall procedure twice, with and without them. The adoption of each measure has a certain cost and leads to a certain change in the emission distributed over the regional territory.

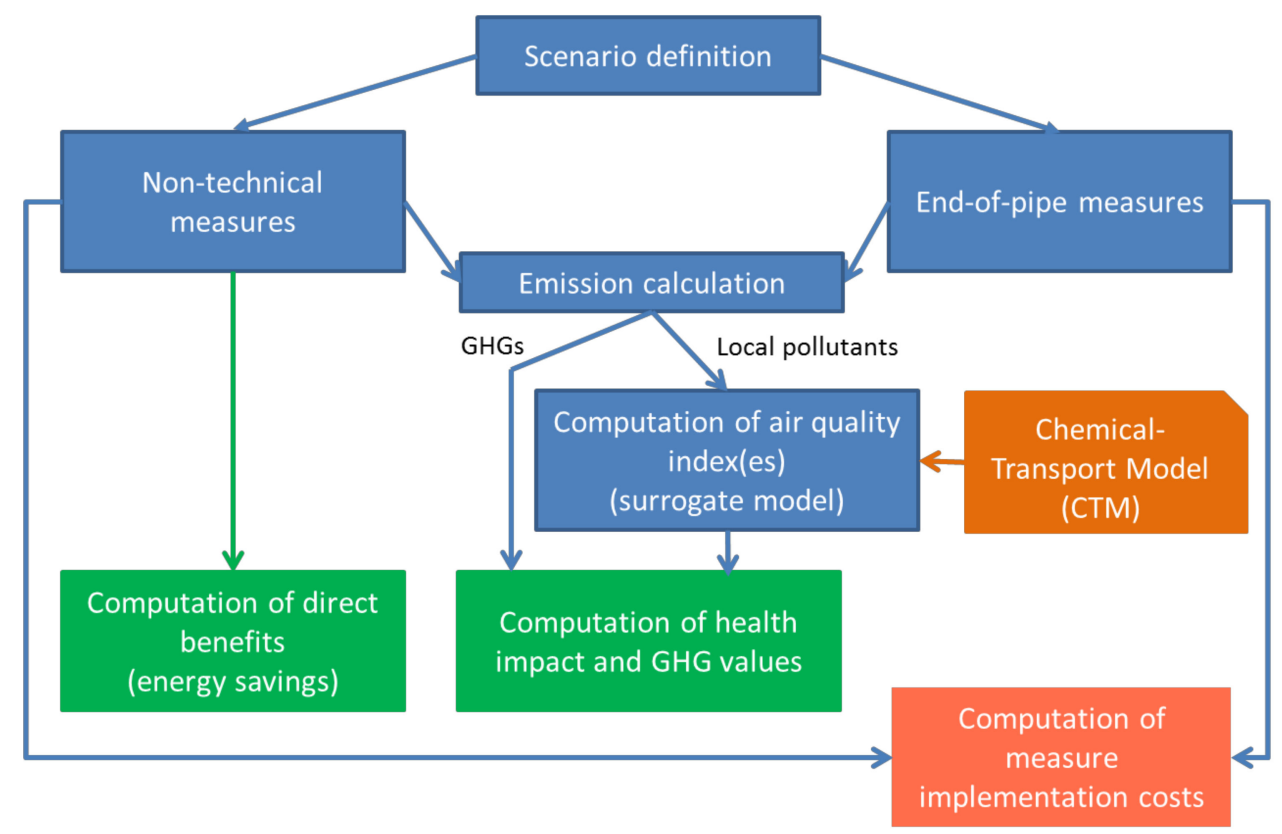

Figure 1. Scheme of the overall assessment procedure.

Since the implementation of a full chemical transport model for the assessment of the emissions reductions will be computationally too heavy, the RIAT+ evaluation tool adopts a surrogate model, calibrated on few CTM results [36]. From the results of the surrogate model (Figure 1), using the well-known impact pathway approach, it is possible to evaluate the improvements in the health of the population and the consequent reduction in external pollution costs. As to the value of GHG emission reduction, whose impact is global and thus does not change with their distribution over the regional territory, it can be computed directly from the emissions.

The final economic assessment is thus obtained by comparing the sum of energy savings and external cost reductions (pollution and GHG) with the implementation costs of the corresponding measures.

\subsection{The Evaluation Tool}

The RIAT+ system (http:/ / www.riatplus.eu), developed in EU OPERA project, has been built in order to help decision makers to design optimal emission reduction strategies to improve air quality in a regional domain at the minimum (industrial and/or external) costs. The system assimilates the specific features of the domain by receiving in input regional datasets for the following:

- chemical regimes and meteorology, through domain specific surrogate models;

- precursor emissions (NOx, $\mathrm{VOC}, \mathrm{NH}_{3}, \mathrm{SO}_{2}$, and primary PM10) including sources outside the domain area;

- emission abatement measures detailed per activity sector including information on emission removal efficiency, costs, and application rates;

This tool, a stand-alone application, has been previously used to assess and design air quality plans in a number of regions, such as Alsace, Emilia-Romagna, Great Brussels, and Porto.

RIAT+ implements the two different decision methodologies according to the DPSIR scheme, as adopted by the EU, namely "scenario analysis," through which experts' defined emission reduction measures are assessed by the model, like in the case at hand, and "optimization." In particular, the last 
approach is implemented as a multi-objective optimization problem that finds the best value of a suitable air quality index (AQI) at minimum total (i.e., implementation plus external) cost:

$$
\begin{gathered}
\min _{u} J(u)=\min _{u}[A Q I(u) C(u)] \\
\text { Subject to } F(u) \leq 0
\end{gathered}
$$

where

- $\quad A Q I$ is one (or a combination of) selected AQI depending on the decision variables $u$ (several different AQIs involving PM, NOx, and ozone are available in the system);

- $C$ is the internal cost for the implementation of abatement measures;

- $F$ constrains the decision variables in a feasible set, considering application feasibility, mutual exclusion of measures, and conservation of the mass (see [6], for details).

To apply both these methodologies in a way that is computationally feasible in real world applications, RIAT+ includes surrogate air quality models linking emissions (Pressures) to an AQI (State). Such a model is used to substitute chemical transport model, whose adoption is impossible due to extremely high computational requirements. The surrogate models applied are based on artificial neural networks (ANNs) trained to replicate the results of CTM simulations [37]. Neural networks, together with a range of other techniques (Gaussian kernel, neuro fuzzy network, etc.), have been widely used in machine learning to solve classification and pattern recognition problems [38]. In this work, the neural network properties of nonlinear approximator are exploited. In fact, ANNs are able to describe nonlinear functions such as those involved in the generation of secondary air pollutants, e.g., ozone. They can be identified with a two steps procedure: (1) the definition of the net structure (input variables, complexity) and (2) the tuning of the parameters for the specific domain and air quality index. ANN structures should be selected according to the essential characteristics of the original model. Due to atmospheric transport, the air quality indices are not dependent only on cell-specific precursor emissions. For this reason, the ANN models should also consider as input the surrounding emissions and their combination through the local meteorology. This can be achieved by adopting as input to the network the sum of pollutant emissions in the adjacent area to each domain cell (a square of $6 \times 6 \mathrm{~km}^{2}$ in this study) in the range of some tens of kilometers (larger for pollutants such as ozone that have slower dynamics). After the choice of the input variables, the surrogate models require the determination of the number of neurons to adopt, the definition of the "activation function," usually a nonlinear function, and the selection of the model parameters-the so-called weights and biases of all neurons.

In the second step (training), the weights of the ANNs are modified through specific algorithms to replicate a set of CTM scenarios representing the range of precursor emissions / AQIs that the surrogate model should be able to evaluate. The selection of the scenarios to be simulated by the CTM is called the "design of experiment." The number of these scenarios needs to be as small as possible due to the computational times of CTMs, but they should represent the cause-effect relationships between precursor emissions and AQIs.

The solution provided by RIAT+ for a certain plan can be analyzed through different dimensions: costs and application levels of measures in different activity sectors, AQI values, spatial distribution of pollutant emissions, and total GHG emission. Once the system is calibrated for a given geographical domain, it is indeed possible to examine the emission fields of various pollutant, the values of different air quality indices, the additional range of variation of measures (i.e., between the plan values and the maximum potential application), and the performances of the current plan in comparison to what could be achieved by applying an optimization approach (see Figure 2). 


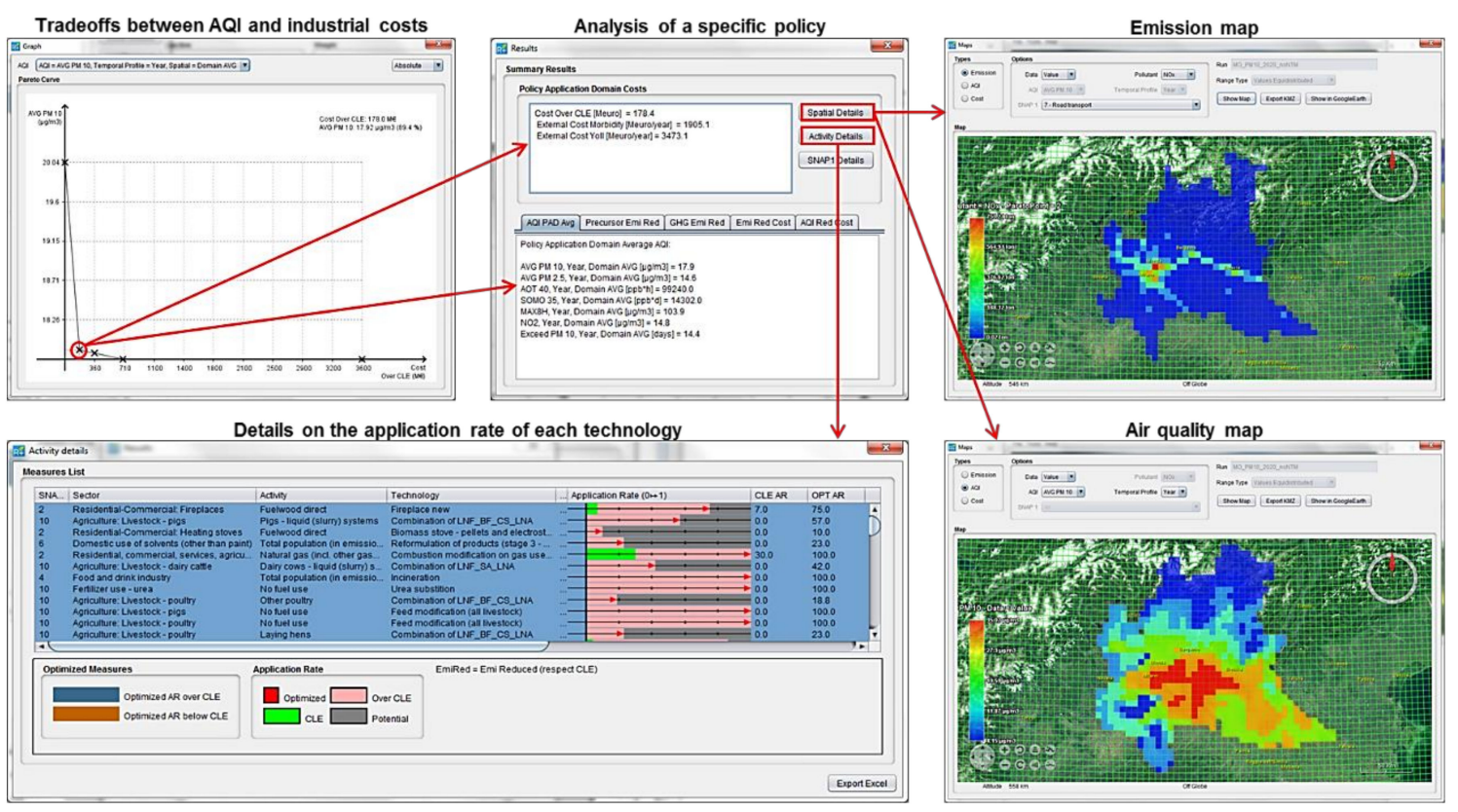

Figure 2. RIAT+ output.

\section{Application to the Lombardy Plan}

\subsection{Measure Implementation}

To analyze the impact of PRIA, the base case situation in the region, with which to compare possible changes, must be computed. In this case, the base case will be the emission and air quality condition in the region in 2020 only on the basis of the Current LEgislation (CLE scenario) that includes a set of abatement measures, in particular belonging to the end-of-pipe category. The corresponding 2020 emissions have been computed by Equation (1) where the reduction term $r_{i p}(u)$ is based on the measure application rates defined in GAINS-Italy [39] in the scenario CIAM 1/2011 developed for the revision of the Gothenburg Protocol [40]. The impact of the plan (whose emissions are also computed with Equation (1) with specific application rates for each individual plan measure-see Section 6.2 for details) will thus be measured as the difference (in benefits and costs) with respect to the CLE scenario. This allows for a fair comparison of CLE 2020 and PRIA scenarios since concentrations (and impacts) are evaluated with the same tool (and hence with the same implied meteorology).

As for the economic values, the implementation costs for some of the measures are specified within the plan itself. This is especially true for some scenario measures involving mainly the change in certain regulations or incentives to behavioral changes. As an example, the fostering of mobility managers, who are supposed to make the transportation of workers of large factories or public institutions more efficient by organizing a systematic car-sharing system, has been quoted at $€ 100,000$ per year, or a sensitization campaign for sustainable mobility at $€ 154,000$. As for end-of-pipe technologies, they have been estimated using the GAINS database [40] and integrated with the evaluation of the cost of better car emission abatement systems (higher EURO categories) developed in a former study [6]. These final costs can be considered as representative of the cost of cleaner technologies, but they do not account for the cost of scrapping an entire old vehicle and substitute it with a newer one.

For efficiency measures, both costs and direct benefits (reduced energy uses) have been taken from different sources reporting values on the local market [41,42]. The assumption is thus that the implementation of the plan will not modify current values (i.e., it will have only a negligible impact on the markets, for instance, of gas and electricity) and that inflation will continue to be very low also for the next few years. As for investment and maintenance costs of new facilities (e.g., solar panels), standard average figures have been assumed: a replacement period of 20 years with a discount rate of $5 \%$ and a yearly cost of maintenance operations equal to $10 \%$ of the cost of investment. A more 
precise evaluation was not possible since the plan does not detail the location or even the actual implementation of such measures from the technical point of view. This also means that no life cycle analysis was made and the costs (and benefits) of any new installations are just their market costs, not the overall cost to society of the materials, construction, use, and decommissioning of the item under consideration. For instance, the cost of substituting diesel-fueled buses with electric ones is the pure difference between the market costs of the two different vehicles (discounted over their plausible operational life).

The evaluation of indirect (or external) costs is more complex. For GHG emissions, they were simply evaluated at the current market value $\left(€ 20 /\right.$ ton $\left._{\mathrm{CO} 2}\right)$ in the EU. This does not clearly represent their value to the global society, and such value is still not known [43].

For traditional pollutants, the classical impact pathway approach [44] was adopted. After the emission scenario is defined, the surrogate model computes the spatial distribution of AQI values. These are then transformed into impacts on population health using dose-response functions and census data, and these impacts are finally monetized assuming a value for each unit impact. For instance, mortality due to poor air quality is measured in terms of YOLL (years of life lost in the entire population under consideration), and each YOLL was quoted at $€ 63,000$, adopting the value defined in other European studies [45].

Given the quality of available information and the general agreement on its hazard to human health, only PM10 has been used to compute external costs. Indeed, $\mathrm{NOx}$ and $\mathrm{O}_{3}$, which were also computed by RIAT+, sometimes exceed the admissible limits or reference values in the region; however, as recently shown by the ESSIA study, specific on short-term effects of air pollutant in the Lombardy region, [46] $\mathrm{NO}_{2}$ and PM concentrations are two indicators of the same exposition, but PM is more related to the biological effects of air pollution. Indeed, how to correctly account for high concentrations of both NOx and PM10 is not yet clear $[47,48]$. We have thus assumed that PM10 effects are stronger and those of other pollutants are covered by PM10. On the other side, ozone, which is a typical summer problem because it needs strong solar radiation to form, has perceivable effects on the vegetation, but the evidence for long-term effects on human health is less conclusive [49].

The data needed for the evaluation of external costs are derived from the national and regional censuses [50] and concern the population living in each cell of the considered domain, subdivided into categories-asthmatic, children (below 14), adults, and seniors (above 65) - in order to take into account the differences on the reaction of each category to PM10 pollution. According to the recent European projects (see, for instance, [4]), the considered impacts range from simple cough and restricted activity days (RADs) to cerebrovascular problems and chronic bronchitis. Related costs go from some hundred euros per case (e.g., per 1 RAD) to about $€ 200,000$ for a case of chronic bronchitis, the treatment of which lasts for the entire life of the patient.

\subsection{Surrogate Model Development}

The neural networks implementing the surrogate models have been trained through a back propagation algorithm. These models have been successfully applied in a variety of previous works $[5,23]$.

TCAM (Transport Chemical Aerosol Model) [51] simulations have been used to define the dataset used for training and validation. TCAM is a three-dimensional Eulerian model that can simulate the main tropospheric physicochemical phenomena involving aerosols and gas phase pollutants. The model has been validated in the framework of the Po Valley Modeling Intercomparison (POMI) project [52].

The design of experiments defined the scenarios to be simulated with such a model in order to determine the datasets applied in the identification and the validation of ANN models. Among such simulations, also some extreme cases must be considered, namely cases in which the precursor emissions assume the plausibly minimum and maximum values. To address this issue, two scenarios, $L$ (Low) and $H$ (High), have been defined by assuming a $15 \%$ further reduction below the Maximum Feasible Reduction (MFR), i.e., the minimum emission technically achievable, and a $15 \%$ additional 
emission above those corresponding to CLE scenario. These two extreme scenarios clearly do not represent realistic cases (emissions below MFR are infeasible and above CLE are not allowed), but they are assumed as the bounds that the models can face during the simulations.

Between these, 14 scenarios have been evenly built, covering the space between $L$ and $H$ emission values using an algorithm based on Sobol sequences [53] ensuring a uniform distribution of numbers among the extremes. The emission of precursor $p$ in each scenario is computed as a different linear combination of the extremes $L$ and $H$.

The corresponding emission range for the different precursors is presented in Table 1, while the corresponding AQI range is presented in Table 2 along with the values resulting from the PRIA scenario to verify that the last indeed falls within the limits for which the ANN models were calibrated and tested. It can be seen that a limited number of cells (5\%) shows SOMO35 values slightly higher than the maximum presented during the training phase. For these cells, the neural network output can be seen as a linear extrapolation starting from the training dataset maximum.

Table 1. Minimum, average, and maximum precursor emission values over the domain cells considering all the scenarios used for training.

\begin{tabular}{cccc}
\hline Emissions [Ton/Year] & Min & Mean & Max \\
\hline $\mathrm{NH}_{3}$ & 0.0 & 52.9 & 1566 \\
$\mathrm{NOx}$ & 0.0 & 95.9 & 11,435 \\
$\mathrm{VOC}$ & 0.0 & 148.9 & 7009 \\
$\mathrm{PM} 10$ & 0.0 & 17.3 & 809 \\
$\mathrm{PM}_{25}$ & 0.0 & 12.4 & 728 \\
$\mathrm{SO}_{2}$ & 0.0 & 20.7 & 15,699 \\
\hline
\end{tabular}

Figure 3a shows the scatter plots of the validation of a neural network to compute PM10 mean yearly concentrations, while Figure 3b, showing another neural network, reproduces SOMO 35 (the yearly sum of the daily maximum of 8-h running average of ozone over $35 \mathrm{ppb}$ ), an indicator of health exposure recommended by WHO, and Figure $3 \mathrm{c}$ shows the validation scatter plot for yearly $\mathrm{NO}_{2}$ concentrations. These figures show, for the different cells of the domain, how much the AQI simulated by means of neural networks deviates from the value computed by the deterministic model. A point lies on the bisecting line when the values are identical for both models. The dotted lines highlight when the ANN output is twice or half that of the CTM.

Table 2. Minimum, average, and maximum air quality index (AQI) values over the domain cells for the training and the scenarios in the Air Quality Plan for the Lombardy Region (PRIA).

\begin{tabular}{ccccccc}
\hline & \multicolumn{3}{c}{ All Scenarios } & \multicolumn{3}{c}{ PRIA } \\
\hline AQI & $\min$ & mean & $\max$ & $\min$ & $\operatorname{mean}$ & $\max$ \\
average PM10 $\left[\mu \mathrm{g} / \mathrm{m}^{3}\right]$ & 2.3 & 19.5 & 43.0 & 3.7 & 18.8 & 34.2 \\
SOMO35 $\left[\mu \mathrm{g} / \mathrm{m}^{3} \cdot \mathrm{d}\right]$ & 1222.3 & $11,740.0$ & $19,426.0$ & 5752.0 & $14,965.0$ & $21,368.7$ \\
average $\mathrm{NO}_{2}\left[\mu \mathrm{g} / \mathrm{m}^{3}\right]$ & 0.5 & 21.7 & 108.3 & 1.21 & 10.0 & 60.7 \\
\hline
\end{tabular}


The scatter plots and the statistical indicators values (correlation, mean squared error-mse) show a close adherence of the surrogate models to TCAM results. The points of the scatter are all very close to the bisecting line, the correlation values are close to 1 , and the mean squared error is low in all the cases.
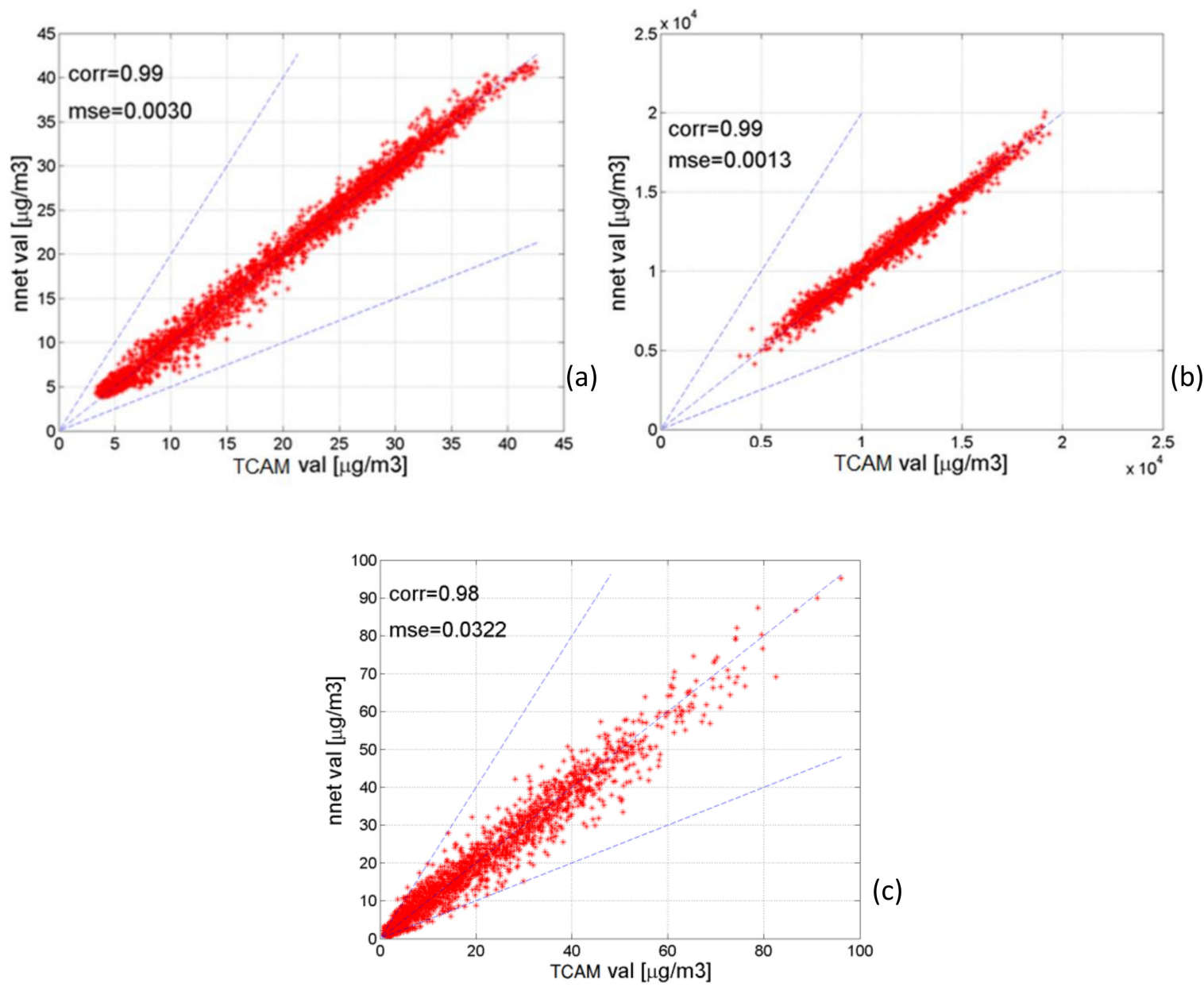

Figure 3. Validation scatter plots for average PM10 (a), SOMO35 (b), and average $\mathrm{NO}_{2}$ (c) computed by the neural network model vs. the transport chemical aerosol model (TCAM).

\section{Results}

\subsection{Air Quality of the Region}

The effect on air quality of PRIA measures application can be seen, in terms of average yearly $\mathrm{PM}_{10}$ concentrations in Figure 4. The figure shows the maps for the CLE 2020 scenario (base case) and the effect of the application of PRIA measures. Reductions can be detected mainly in the area around Milan (densely populated and industrialized) where the highest reduction shows a decrease of $3.8 \mu \mathrm{g} / \mathrm{m}^{3}$. In the northern part of the region, with low population and traffic density, the reduction is much less evident. 

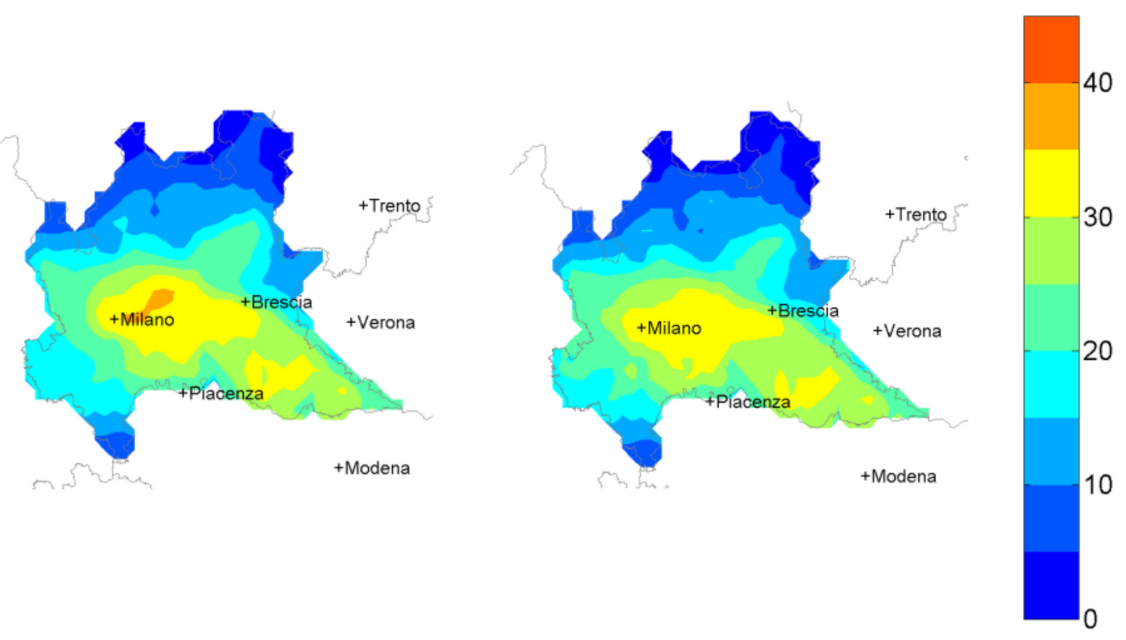

Figure 4. Maps of yearly PM10 concentrations for Current LEgislation (CLE) scenario (left) and PRIA scenario (right).

To further analyze air quality conditions, Figure 5 reports the SOMO35 maps. Due to the well-known non-linear relationships involving ozone, some areas are characterized by a reduction (areas around the city of Milan), while others have increased values (central and southern part of the domain). The highest reduction and increase detected are respectively $1836 \mu \mathrm{g} / \mathrm{m}^{3} \cdot \mathrm{d}$ and $1803 \mu \mathrm{g} / \mathrm{m}^{3} \cdot \mathrm{d}$, while the overall average reduction is $258 \mu \mathrm{g} / \mathrm{m}^{3} \cdot \mathrm{d}$, which represents $1.7 \%$ of the domain average.
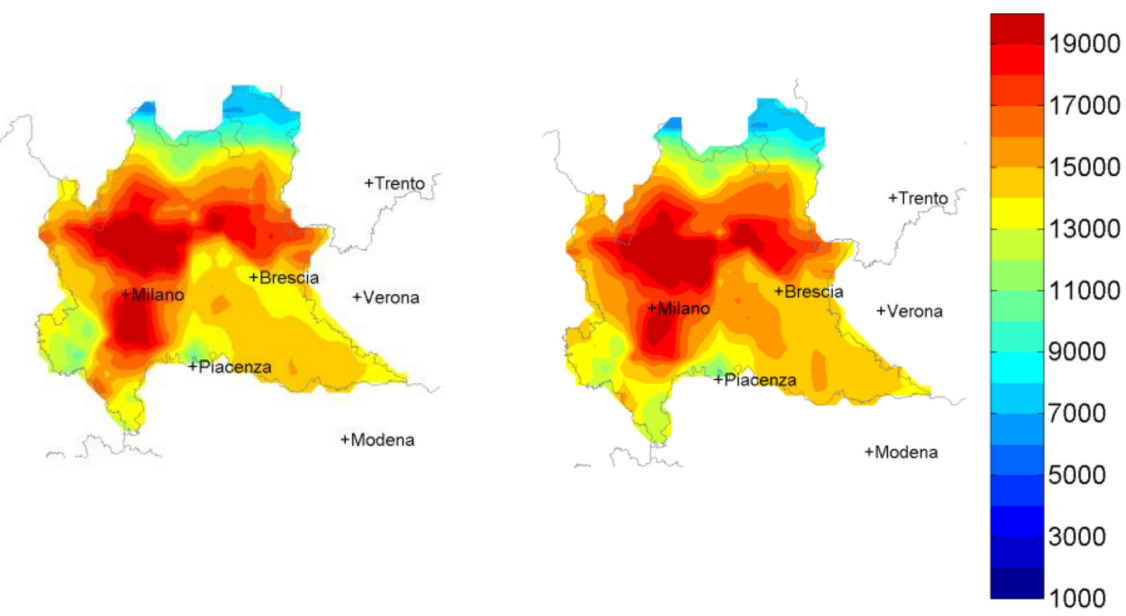

Figure 5. Maps of yearly SOMO35 values for CLE scenario (left) and PRIA scenario (right).

As for NOx, the yearly average concentrations are shown in Figure 6 for the CLE 2020 scenario and PRIA scenario. Reductions can be detected, similarly to PM10, in the area around Milan; however, in addition to that, there is also a high impact of PRIA policies in the southwestern part of the domain. Other parts of the domain undergo a moderate increase in NOx concentrations. The domain cell showing the highest reduction has a decrease of $18.86 \mu \mathrm{g} / \mathrm{m}^{3}$, while the overall average reduction is $3.01 \mu \mathrm{g} / \mathrm{m}^{3}$, i.e., $21.4 \%$ of the domain average. 


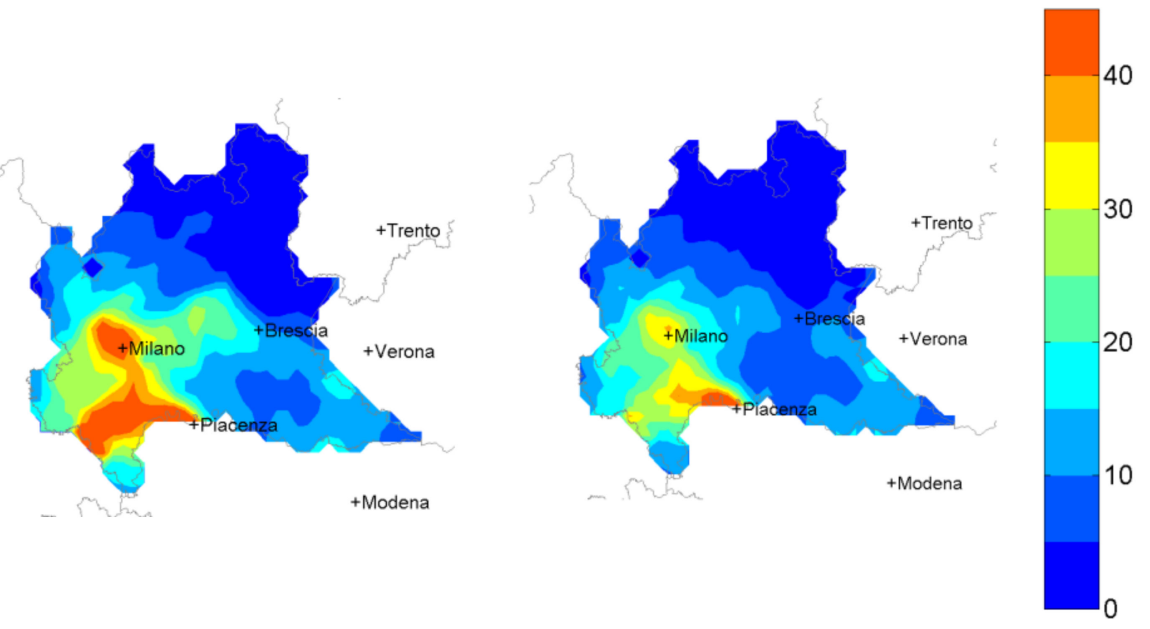

Figure 6. Maps of yearly NOx values for CLE scenario (left) and PRIA scenario (right).

As for $\mathrm{CO}_{2}$ emissions, whose spatial distribution is not relevant, GHG being a global problem, the overall plan would entail a reduction of about $13 \mathrm{Mt} /$ year, or about $18 \%$ of the regional emission in 2014.

\subsection{Examples of Individual Measures}

The tool adopted for this study allows for a fast screening of each individual measure to understand its air quality impact and the consequent external costs, thus allowing balancing the costs and benefits deriving from its implementation and determining the individual measures with the highest efficiency.

For instance, an efficiency measure providing detailed heat accounting for buildings reduces energy consumption in urban areas by almost 46 million GJ/y with a $€ 39 \mathrm{M} / \mathrm{y}$ cost. The direct benefit of the measure (a reduction in gas consumption since practically all the heating in the region is fueled by gas) is worth about $€ 2.4 \mathrm{G} / \mathrm{y}$, resulting in yearly reductions of 255 tons of VOC, 2700 tons of NOx, and 39 tons of PM10. The reduction in GHG emission will reach $2.7 \mathrm{Mtons}_{\mathrm{CO} 2}$, with a value of about $€ 54 \mathrm{M} / \mathrm{y}$ at current price ( $€ 20 /$ ton). The reduced morbidity can be valued at $€ 6.7 \mathrm{M}$, and the reduced mortality at $€ 12.2 \mathrm{M}$ per year.

The replacement of vehicles with standards older than EURO 3 with EURO 6 vehicles would result in 246,000 substitutions in 2020, with a traveled distance of 4 billion kilometers costing $€ 5.65 \mathrm{M} / \mathrm{y}$ in total, no direct benefit (it is considered an end-of-pipe measure, thus without GHG emission reduction as indeed happened in the past years despite the introduction of newer vehicles), and annual emission reductions of 433 tons of VOC, 234 tons of PM10, and 6385 tons of NOx. The reduction in primary and secondary PM10 concentrations particularly in urban centers translates into an annual benefit of $€ 13.7 \mathrm{M}$ due to a reduction in morbidity and $€ 25 \mathrm{M}$ due to the reduced mortality.

One scenario measure-the development of a new underground line in the urban area of Milan for a $€ 3.96 \mathrm{M} / \mathrm{y}$ cost (considering a $5 \%$ discount over 25 years) - has been estimated to reduce the yearly mileage driven by cars by 136 million kilometers. Resulting in a diesel and gasoline reduction worth $€ 7.13 \mathrm{M} / \mathrm{y}$, with consequent emission reductions of 1 ton of PM10, 9 tons of NOx, 2 tons of VOC, and 20.4 ktons $\mathrm{CO}_{2}$. These emission reductions have a small impact on the overall regional air quality and thus affect the health of a limited portion of the population. This is not surprising considering that the overall regional car mileage is larger by nearly three orders of magnitude compared with the reduction foreseen for this measure and for the traffic sector alone, which is only a part, even if large, of the regional emitting activities. 


\subsection{Cost-Benefit Analysis}

The overall results can be summarized in Table 3, which shows the estimated costs and benefits of PRIA measures in 2020, computed as the difference from CLE. Measures are aggregated into four categories: private transport, public and other transport modes (such as cycling), thermal energy, and electricity. As previously highlighted, direct costs and direct benefits are evaluated with reference to average local market values. The health benefits, instead, are evaluated considering their value for the society, so these categories are not directly comparable.

Table 3. Costs and benefits of the PRIA measures by categories.

\begin{tabular}{ccccc}
\hline & \multicolumn{3}{c}{$\mathbf{2 0 2 0}(\mathbf{M} € /$ Year $)$} \\
\hline & Measure costs & Direct benefits & Health benefits PM10 & GHG $\left(€ 20 / \mathbf{t}_{\mathrm{CO} 2}\right)$ \\
Private transport & 208 & 966 & 57 & $\sim 0$ \\
Public transport & 846 & 1454 & $\sim 0$ & 21 \\
Electric energy & 2590 & 2058 & $\sim 0$ & 122 \\
Thermal energy & 3781 & 8688 & 37 & 160 \\
Total PRIA & 7425 & 13,166 & 80 & 303 \\
\hline
\end{tabular}

Several considerations can be made based on this table. First, the allocation of costs to the electricity sector or to thermal energy is partly arbitrary, because some of the interventions act on both. In this analysis, the costs have been divided according to the relative ratio of the benefits, because these clearly belong to a specific sector. Secondly, measures involving electric energy production are expensive and provide, in return, direct benefits approximately of the same magnitude, without much improvement in air quality. The reason behind this can be found in the high stacks of power plants with strictly controlled emissions that are also generally not located inside urban centers. Therefore, abatement measures applied to these emission sources do not result in significant impacts. On the other hand, the shift from traditional electricity mainly produced by thermal plants to renewable sources allows for a consistent reduction in $\mathrm{CO}_{2}$ emission and thus provides significant economic benefits. Considering thermal energy, the balance is definitely positive. In fact, more sustainable techniques can be applied to produce it replacing low altitude urban emissions with a high emission source. This also means that these actions provide a significant reduction in GHG emissions.

The measures adopted in private transport show savings that significantly outweigh the costs and have a higher impact over the improvement in air quality and health. Indeed, according to RIAT+ results, the conversion to less polluting vehicles provides the highest return in terms of benefits for human health per unit investment.

It is worth noting that the sum of the health benefits for each individual measure of the plan is not equal to the health benefits of the overall plan due to the non-linearities involved in secondary pollutants generation. This is not the case for GHG reduction, which is simply the sum of the effects of individual measures.

The direct costs can be defined as a yearly average fraction of the useful life of the measures. This does not mean that the positive assessment of the plan emerging from this analysis can be obtained for each year. In a first period, the concentration of investments will result in a negative cash flow; in a second period, defined by the useful life of the measures (usually 15-20 years), the cash flow becomes positive and resets the deficit in 5-10 years in most cases.

As already mentioned, RIAT + can be used to evaluate the trade-off between the (additional) cost of end-of-pipe measures and certain AQIs. Again, with reference to PM10, for instance, the solutions of the multi-objective problem defined in Section 4.2 are shown in Figure 7. This Pareto front represents, in the objective space, the non-dominated solutions for different costs. The solution marked as $\mathrm{P}$, for instance, has a total cost of $€ 275 \mathrm{M}$ /year and corresponds to a situation in which the highest decrease in PM10 at some point of the domain is $6.14 \mu \mathrm{g} / \mathrm{m}^{3}$, while the overall average reduction is about $1.85 \mu \mathrm{g} / \mathrm{m}^{3}$, i.e., $9.7 \%$ of the domain average. The main interest of this graph is, however, in the 
illustration it provides of the range of air quality values that can be obtained: with a small expenditure (about $5 \%$ of the cost of full adoption of the best technologies), the average PM10 concentration may be decreased by $99 \%$ of the allowable range, and, even with a very large investment in end-of-pipe technologies, the improvement in air quality cannot go much further.

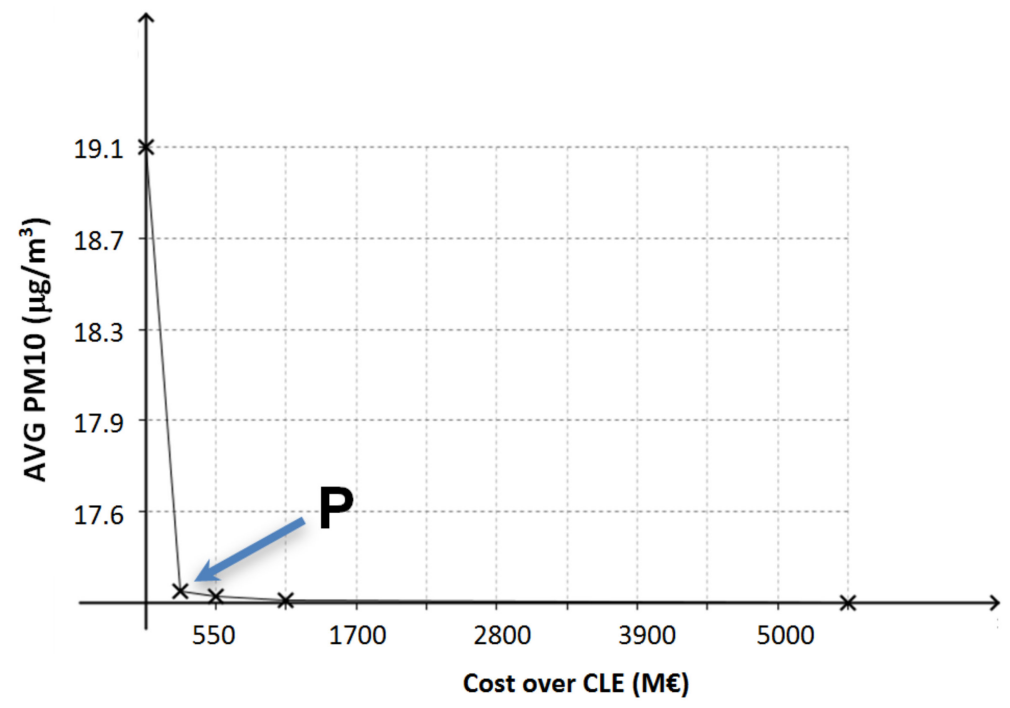

Figure 7. Pareto front of optimal PM10 concentration plans vs. additional cost of end-of-pipe measures.

A comparison of the emission reductions foreseen by the PRIA scenario and P solution shows that the PRIA strategy is mainly focused on the reduction in primary particulate matter (both PM10 and PM2.5 are reduced twice as much as in P), while the P solution focuses more on the other precursors, especially $\mathrm{NH}_{3}$, whose emissions are reduced four times more than in the PRIA strategy. Health benefits are higher in the case of solution P due to the lower PM10 concentrations reached.

The two plans are not comparable under many respects. They include different measures in different sectors and plan $\mathrm{P}$ does not consider the implementation problems possibly related to some of the measures. Solution P is only based on the optimization of average PM10, while other objectives may be relevant, and the costs used for the evaluation of $\mathrm{P}$ are only those due to the application of end-of-pipe technologies, while those of PRIA include those of many non-technical measures. These results are however useful, since they indicate the importance of additional actions for the reduction in ammonia, which could be included in the period plan revisions.

\subsection{Sensitivity Analysis}

All costs and benefits presented above have a certain degree of uncertainty, particularly because they refer to the situation in 2020. We have thus tried to assess the probability of an inversion of the results, namely the probability that the overall costs of the plan might exceed the expected benefits. If we assume a normal distribution of all economic values with a standard deviation of $15 \%$ of the average, the probability that the benefits exceed the costs is close to one, as can be seen in Figure 8 (left). Only in the electric sector is the situation reversed, as shown in Figure 8 (right), but with a relatively large intersection.

Looking only at the value of $\mathrm{CO}_{2}$ emissions, the conclusion may be different. Figure 9 shows the variation in the EU market price of $\mathrm{CO}_{2}$ emissions from the adoption of PRIA to 2018. After a long period of stagnation, with prices oscillating around $€ 5 /$ ton, the price increased to more than $€ 20 /$ ton. If we disregard for a while all the preceding caveats and compare all the monetary values in Table 3 , the value of environmental impacts (human health and GHG) remain limited to about $6.5 \%$ of the net benefits of the entire plan and thus, even a strong variation of the $\mathrm{CO}_{2}$ price, will not substantially change the situation. One may note, however, that the balance between local and global impacts has reversed since the adoption of the plan: until 2016, the (local) impact on human health was larger than 
the global one (as measured by $\mathrm{CO}_{2}$ market price), while today the situation has reversed. This trend will certainly continue since projections indicate a further increase in $\mathrm{CO}_{2}$ price in the future and the progressive adoption of pollution abatement measures will decrease the impact on human health.

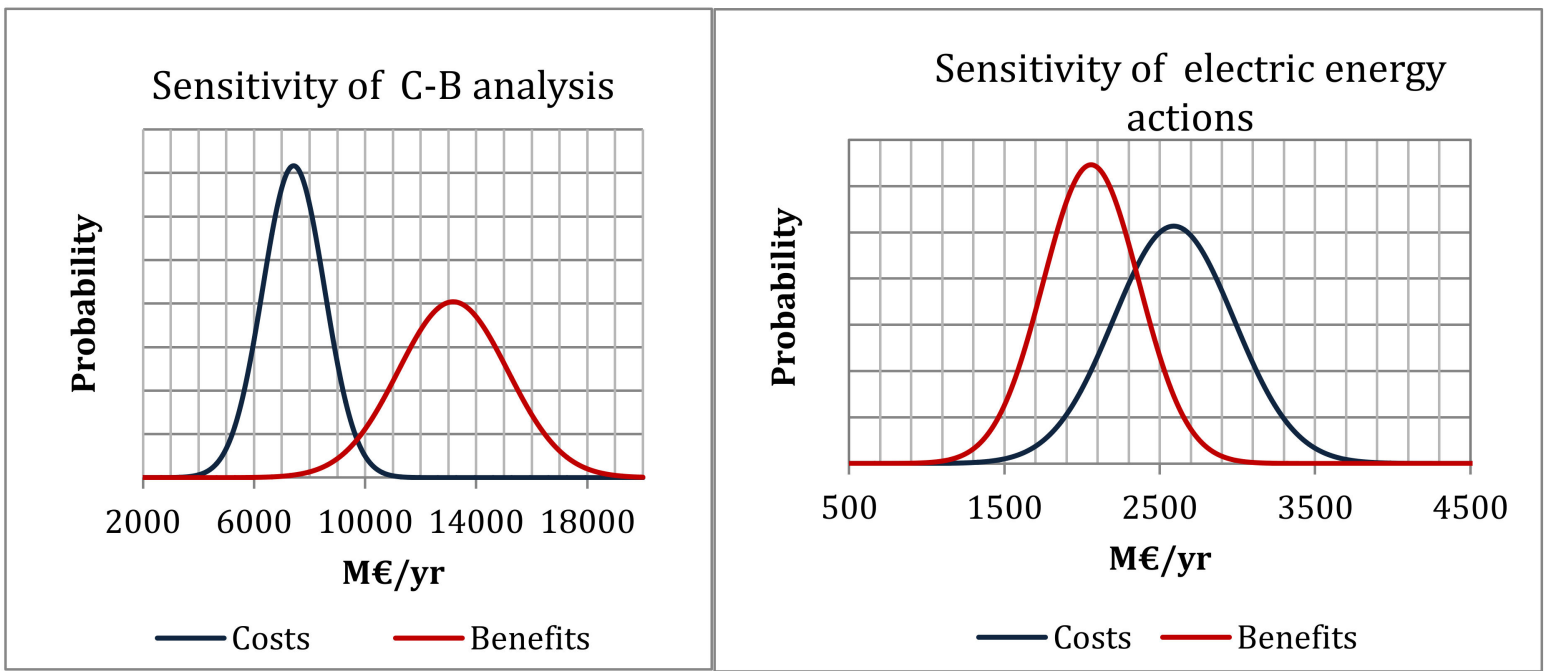

Figure 8. Probability plot for the sensitivity of cost-benefit analysis considering all the macro-areas (left) and only electric energy sector (right).

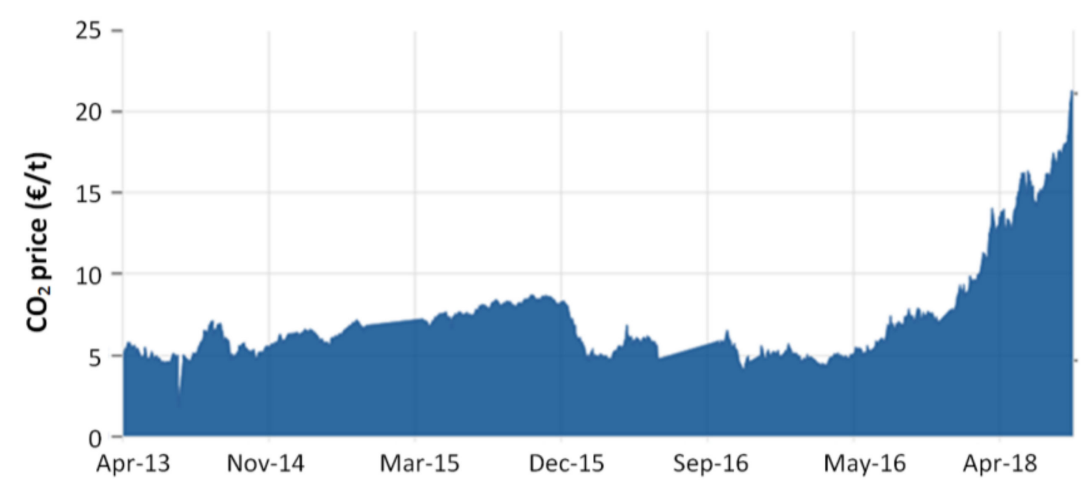

Figure 9. EU market price of $\mathrm{CO}_{2}$ emissions (data from [54]).

\section{Conclusions}

The current air quality plan of the Lombardy region (PRIA) has been evaluated in this study from environmental and economic viewpoints. We have proposed a methodology that allows one to perform an estimate of the economic cost of measure implementation as well as the direct benefits in terms of energy savings, public health benefits, and GHG emission reduction.

In terms of air quality, the results show that the plan can provide a widespread reduction in NOx yearly mean concentrations (21\%) and GHGs (18\%) emissions. Ozone is reduced mainly in urban areas, while it slightly increases in the rural part of the domain. Finally, yearly PM10 concentrations were observed to decrease in the most densely populated area of the domain.

As in other cost-benefit analyses of air quality plans (e.g., [32,33]), despite the high costs that society must cover for the implementation of the planned measures, the resulting direct benefits are superior, with a high probability. Population health level will also be improved even if the corresponding benefits are much smaller than the direct ones. The ability to significantly reduce pollutant concentrations by implementing actions only in Lombardy is limited, and higher effects can only be achieved through joint actions involving all regions in Po Valley. At current EU prices, the reduction in GHG emissions has a higher value than the estimated external costs due to local air pollution. Given these limitations, from the viewpoint of air quality, regional authorities should first 
implement actions on domestic heating and private traffic, since other traffic modes have a negligible impact, and electric energy, the pollution of which is emitted far from residential sites, also has a relatively low impact.

The experience developed in this study allows for a number of considerations. First, studies for the development of regional plans should try to include the impacts on a population's health and GHG emissions and their value in economic terms. Second, the inclusion of all possible actions that may lead to an improvement in air quality into a unique plan poses a series of methodological questions. Clearly, the decision to build a new metro line is not taken purely looking at air quality and will have significant impacts in many other sectors (traffic speed, availability of parking lots, noise, accidents, etc.). How can we attribute costs and benefits of such a measure to air quality? In the present case, even when considering the full cost of the measure, the balance seems positive, but this is because the reduction of energy consumption is much greater than the improvement in air quality and its consequent reduced impacts. Perhaps there is little use in trying to devise and evaluate a "pure" air quality plan: only a coordinated set of actions involving mobility, energy, air pollution, and the environment in general can be jointly estimated and, possibly, finally judged with the involvement of all stakeholders.

Author Contributions: Conceptualization: G.G.; methodology: C.C., G.M., and M.V.; software: F.F. and E.T.; writing—original draft: M.V.; writing—-review \& editing: G.G.

Funding: This research was partially funded by the VALUTA project of ARPA Lombardia.

Acknowledgments: The authors are grateful to G. Lanzani and E. Angelino, ARPA Lombardia, for supporting the activity and commenting the manuscript.

Conflicts of Interest: The authors declare no conflict of interest.

\section{References}

1. Åstrom, S.; Yaramenka, K.; Mawdsley, I.; Danielsson, H.; Grennfelt, P.; Gerner, A.; Ekvall, T.; Ahlgren, E.O. The impact of Swedish $\mathrm{SO}_{2}$ policy instruments on $\mathrm{SO}_{2}$ emissions 1990-2012. Environ. Sci. Policy 2017, 77, 32-39. [CrossRef]

2. EU, Commission and Parliament. Directive 2008/50/ec of the european parliament and of the council of 21 May 2008 on ambient air quality and cleaner air for Europe. Off. J. Eur. Union 2008, 29, 169-212.

3. Guariso, G.; Volta, M. Air Quality in Europe: Today and Tomorrow. In Air Quality Integrated Assessment: A European Perspective; Guariso, G., Volta, M., Eds.; Springer International Publishing: Cham, Switzerland, 2017; pp. 1-8.

4. Thunis, P.; Miranda, A.; Baldasano, J.M.; Blond, N.; Douros, J.; Graff, A.; Janssen, S. Overview of current regional and local scale air quality modelling practices: Assessment and planning tools in the EU. Environ. Sci. Policy 2016, 65, 13-21. [CrossRef]

5. Carnevale, C.; Finzi, G.; Pederzoli, A.; Turrini, E.; Volta, M.; Guariso, G.; Gianfreda, R.; Maffeis, G.; Pisoni, E.; Thunis, P.; et al. Exploring trade-offs between air pollutants through an Integrated Assessment Model. Sci. Total Environ. 2014, 481, 7-16. [CrossRef] [PubMed]

6. Carnevale, C.; Finzi, G.; Pisoni, E.; Volta, M.; Guariso, G.; Gianfreda, R.; Maffeis, G.; Thunis, P.; White, L.; Triacchini, G. An integrated assessment tool to define effective air quality policies at regional scale. Environ. Model. Softw. 2012, 38, 306-315. [CrossRef]

7. Guariso, G.; Maione, M.; Volta, M. A decision framework for Integrated Assessment Modelling of air quality at regional and local scale. Environ. Sci. Policy 2016, 65, 3-12. [CrossRef]

8. Viaene, P.; Belis, C.A.; Blond, N.; Bouland, C.; Juda-Rezler, K.; Karvosenoja, N. Air quality integrated assessment modelling in the context of EU policy: A way forward. Environ. Sci. Policy 2016, 65, 22-28. [CrossRef]

9. Cecchel, S.; Chindamo, D.; Turrini, E.; Carnevale, C.; Cornacchia, G.; Gadola, M.; Panvini, A.; Volta, M. Impact of reduced mass of light commercial vehicles on fuel consumption, $\mathrm{CO}_{2}$ emissions, air quality, and socio-economic costs. Sci. Total Environ. 2018, 613-614, 409-417. [CrossRef] [PubMed] 
10. Duque, L.; Relvas, H.; Silveira, C.; Ferreira, J.; Monteiro, A.; Gama, C.; Rafael, S.; Freitas, S.; Borrego, C.; Miranda, A.I. Evaluating strategies to reduce urban air pollution. Atmos. Environ. 2016, 127, 196-204. [CrossRef]

11. Vautard, R.; Builtjes, P.H.J.; Thunis, P.; Cuvelier, C.; Bedogni, M. Evaluation and intercomparison of Ozone and PM10 simulations by several chemistry transport models over four European cities within the CityDelta project. Atmos. Environ. 2010, 41, 173-188. [CrossRef]

12. Vlachokostas, C.; Achillas, C.; Moussiopoulos, N.; Banias, G. Multicriteria methodological approach to manage urban air pollution. Atmos. Environ. 2011, 45, 4160-4169. [CrossRef]

13. Wang, Q.; Dai, H.-N.; Wang, H. A Smart MCDM Framework to Evaluate the Impact of Air Pollution on City Sustainability: A Case Study from China. Sustainability 2017, 9, 911. [CrossRef]

14. Relvas, H.; Miranda, A.I.; Carnevale, C.; Maffeis, G.; Turrini, E.; Volta, M. Optimal air quality policies and health: A multi-objective nonlinear approach. Environ. Sci. Pollut. Res. 2017, 24, 13687-13699. [CrossRef] [PubMed]

15. Pisoni, E.; Carnevale, C.; Volta, M. Multi-criteria analysis for PM10 planning. Atmos. Environ. 2009, 43, 4833-4842. [CrossRef]

16. Carnevale, C.; Pisoni, E.; Volta, M. Selecting effective ozone exposure control policies solving a two-objective problem. Ecol. Model. 2007, 204, 93-103. [CrossRef]

17. Guariso, G.; Pirovano, G.; Volta, M. Multi-objective analysis of ground-level ozone concentration control. J. Environ. Manag. 2004, 71, 25-33. [CrossRef] [PubMed]

18. Moussiopoulos, N.; Douros, J.; Reis, R.F. Merlin: The study of urban air quality in 20 European cities. In Proceedings of the Ninth International Conference on Environmental Science and Technology, Rhodes, Greece, 1-3 September 2005; pp. 1044-1049.

19. Vlachokostas, C.; Achillas, C.; Moussiopoulos, N.; Hourdakis, E.; Tsilingiridis, G.; Ntziachristos, L.; Banias, G.; Stavrakakis, N.; Sidiropoulos, C. Decision support system for the evaluation of urban air pollution control options: Application for particulate pollution in Thessaloniki, Greece. Sci. Total Environ. 2009, 407, 5937-5948. [CrossRef] [PubMed]

20. Amann, M.; Bertok, I.; Borken-Kleefeld, J.; Cofala, J.; Heyes, C.; Hoeglund-Isaksson, L.; Klimont, Z.; Nguyen, B.; Posch, M.; Rafaj, P.; et al. Cost-effective control of air quality and greenhouse gases in Europe: Modeling and policy applications. Environ. Model. Softw. 2011, 26, 1489-1501. [CrossRef]

21. Mediavilla-Sahagún, A.; ApSimon, H.M. Urban scale integrated assessment of options to reduce PM 10 in London towards attainment of air quality objectives. Atmos. Environ. 2003, 37, 4597-4721. [CrossRef]

22. Carlson, D.A.; Haurie, A.; Vial, J.; Zachary, D.S. Large-scale convex optimization methods for air quality policy assessment. Automatica 2004, 40, 385-395. [CrossRef]

23. Miranda, A.I.; Relvas, H.; Viaene, P.; Janssen, S.; Brasseur, O.; Carnevale, C.; Declerck, P.; Maffeis, G.; Turrini, E.; Volta, M. Applying integrated assessment methodologies to air quality plans: Two European cases. Environ. Sci. Policy 2016, 65, 29-38. [CrossRef]

24. Lefebvre, W.; Vercauteren, J.; Schrooten, L.; Janssen, S.; Degraeuwe, B.; Maenhaut, W.; de Vlieger, I.; Vankerkom, J.; Cosemans, G.; Mensink, C.; et al. Validation of the MIMOSA-AURORA-IFDM model chain for policy support: Modeling concentrations of elemental carbon in Flanders. Atmos. Environ. 2011, 45, 6705-6713. [CrossRef]

25. Mensink, C.; De Vlieger, I.; Nys, J. An urban transport emission model for the Antwerp area. Atmos. Environ. 2000, 34, 4595-4602. [CrossRef]

26. Lefebvre, W.; Schillemans, L.; Op't Eyndt, T.; Vandersickel, M.; Poncelet, P.; Neuteleer, C.; Dumez, J.; Janssen, S.; Vankerkom, J.; Maiheu, B.; et al. Voorstel van Maatregelen om de Luchtkwaliteit te Verbeteren en de Geluidshinder te Beheersen in de Stad Antwerpen (Dutch Report for the City of Antwerp). 2011. Available online: https:/ / anzdoc.com/voorstel-van-maatregelen-om-de-luchtkwaliteit-te-verbeteren-.html (accessed on 25 September 2018).

27. Berkowicz, R.; Ketzel, M.; Jensen, S.S.; Hvidberg, M.; Raaschou-Nielsen, O. Evaluation and application of OSPM for traffic pollution assessment for a large number of street locations. Environ. Model. Softw. 2008, 23, 296-303. [CrossRef]

28. Roy, B. The outranking approach and the foundations of Electre methods. Theory Decis. 1991, 31, 49-63. [CrossRef] 
29. Borrego, C.; Sá, E.; Carvalho, A.; Sousa, S.; Miranda, A.I. Plans and Programmes to improve air quality over Portugal: A numerical modelling approach. Int. J. Environ. Pollut. 2012, 48, 60-68. [CrossRef]

30. Yang, N.; Zhang, Z.; Xue, B.; Ma, J.; Chen, X.; Lu, C. Economic Growth and Pollution Emission in China: Structural Path Analysis. Sustainability 2018, 10, 2569. [CrossRef]

31. Li, S.; Ma, Y. Urbanization, Economic Development and Environmental Change. Sustainability 2014, 6, 5143-5161. [CrossRef]

32. Gao, J.; Yuan, Z.; Liu, X.; Xia, X.; Huang, X.; Dong, Z. Improving air pollution control policy in China-A perspective based on cost-benefit analysis. Sci. Total Environ. 2016, 543, 307-314. [CrossRef] [PubMed]

33. Chae, Y.; Park, J. Quantifying costs and benefits of integrated environmental strategies of air quality management and greenhouse gas reduction in the Seoul Metropolitan Area. Sci. Total Environ. 2011, 39, 5296-5308. [CrossRef]

34. Regione Lombardia. Piano Regionale degli Interventi per la qualità dell'Aria (PRIA). 2013. Available online: http:/ / www.regione.lombardia.it/wps/portal/istituzionale/HP/DettaglioRedazionale/istituzione/ direzioni-generali/direzione-generale-ambiente-energia-e-sviluppo-sostenibile/piano-regionale-interventiqualita-aria-pria/piano-regionale-interventi-qualita-aria-pria (accessed on 17 July 2018).

35. Carnevale, C.; Guariso, G.; Ferrari, F.; Maffeis, G.; Turrini, E.; Volta, M. Incremental Selection of Regional Air Quality Measures. IFAC-PapersOnLine 2018, 51, 85-89. [CrossRef]

36. Carnevale, C.; Finzi, G.; Guariso, G.; Pisoni, E.; Volta, M. Surrogate models to compute optimal air quality planning policies at a regional scale. Environ. Model. Softw. 2012, 34, 44-50. [CrossRef]

37. Carnevale, C.; Finzi, G.; Pederzoli, A.; Turrini, E.; Volta, M. Lazy Learning based surrogate models for air quality planning. Environ. Model. Softw. 2016, 83, 47-57. [CrossRef]

38. Hu, A.; Zhang, L.; Chen, D.; Pedrycz, W.; Yu, D. Gaussian kernel based fuzzy rough sets: Model, uncertainty measures and applications. Int. J. Approx. Reason. 2010, 51, 453-471. [CrossRef]

39. ENEA. GAINS Italy Online. 2018. Available online: http://gains-it.bologna.enea.it/gains/IT/index.login (accessed on 17 July 2018).

40. Amann, M.; Bertok, I.; Borken-Kleefeld, J.; Cofala, J.; Heyes, C.; Höglund-Isaksson, L.; Klimont, Z.; Rafaj, P.; Schöpp, W.; Wagner, F. Cost-Effective Emission Reductions to Improve Air Quality in Europe in 2020. 2011. Available online: https://www.unece.org/fileadmin/DAM/env/documents/2011/eb/wg5/WGSR49/ Informal\%20docs/Info.doc._8_Cost-effective_Emission_Reductions.pdf (accessed on 25 August 2018).

41. Department of Energy, Politecnico di Milano. Costi di Produzione di Energia Elettrica da Fonti Rinnovabili; Internal Report; Department of Energy, Politecnico di Milano: Milano, Italy, 2013. (In Italian)

42. Chiesa, M.; Perrone, M.G.; Cusumano, N.; Ballarin Denti, A.; Bolzacchini, E.; Lorenzoni, A. Integrated measures for air pollution reduction in the Province of Milan. In Abstracts of the Urban Environmental Pollution, UEP 2012; Elsevier: Amsterdam, The Netherlands, 2012.

43. Gies, E. The real cost of energy. Nature 2017, 551, S145-S147.

44. Hurley, W.F.; Hunt, A.; Cowie, H.; Holland, M.; Miller, B.; Pye, S.; Watkiss, P. Methodology for the Cost-Benefit analysis for CAFE:2:Health Impact Assessment; Report to the European Commission, DG Environment, AEAT/ED51014; AEA Technology Environment: Oxon, UK, 2005.

45. Rabl, A.; Holland, M. Environmental Assessment Framework for Policy Applications: Life Cycle Assessment, External Costs and Multi-criteria Analysis. J. Environ. Plan. Manag. 2008, 51, 81-105. [CrossRef]

46. Regione Lombardia. ESSIA, Effetti Effetti Sulla Salute Degli Inquinanti Aerodispersi in Regione Lombardia. 2012. Available online: http:/ / www.regione.lombardia.it/wps/wcm/connect/63ef0b5d-ffcd-49a9-8f8e5cd335276384/ESSIA_RelazioneFinale_WEB.pdf?MOD=AJPERES\&CACHEID=63ef0b5d-ffcd-49a9-8f8e5cd335276384 (accessed on 25 August 2018).

47. Lim, S.S.; Vos, T.; Flaxman, A.D.; Danaei, G.; Shibuya, K.; Adair-rohani, H.; Almazroa, M.A.; Amann, M.; et al. A comparative risk assessment of burden of disease and injury attributable to 67 risk factors and risk factor clusters in 21 regions, 1990-2010: A systematic analysis for the Global Burden of Disease Study 2010. Lancet 2012, 380, 2224-2260. [CrossRef]

48. Billionnet, C.; Sherrill, D.; Annesi-Maesano, I. GERIE Study, Estimating the Health Effects of Exposure to Multi-Pollutant Mixture. Ann. Epidemiol. 2012, 22, 126-141. [CrossRef] [PubMed]

49. Nuvolone, D.; Petri, D.; Voller, F. The effects of ozone on human health. Environ. Sci. Pollut. Res. Int. 2018, 25, 8074-8088. [CrossRef] [PubMed] 
50. ISTAT, Istituto Nazionale di Statistica (National Statistical Institute). 2018. Available online: https: / / www. istat (accessed on 25 August 2018).

51. Carnevale, C.; Finzi, G.; Pederzoli, A.; Pisoni, E. Applying the delta tool to support the Air Quality Directive: Evaluation of the TCAM chemical transport model. Air Qual. Atmos. Health 2014, 7, 335-346. [CrossRef]

52. Pernigotti, D.; Thunis, P.; Cuvelier, C.; Georgieva, E.; Gsella, A.; De Meij, A.; Pirovano, G.; Balzarini, A.; Riva, G.M.; Carnevale, C.; et al. POMI: A model inter-comparison exercise over the Po Valley. Air Qual. Atmos. Health 2013, 6, 701-715. [CrossRef]

53. Sobol, I.M. Uniformly distributed sequences with an additional uniform property. USSR Comput. Math. Math. Phys. 1976, 16, 236-242. [CrossRef]

54. Available online: https://markets.businessinsider.com (accessed on 25 August 2018).

C 2018 by the authors. Licensee MDPI, Basel, Switzerland. This article is an open access article distributed under the terms and conditions of the Creative Commons Attribution (CC BY) license (http:// creativecommons.org/licenses/by/4.0/). 